\title{
Generation enhances semantic processing? The role of distinctiveness in the generation effect
}

\author{
SACHIKO KINOSHITA \\ University of New South Wales, Kensington, New South Wales, Australia
}

\begin{abstract}
The goal of the present study was to investigate the locus of the memory advantage for words that are generated according to a nonsemantic rule (letter transposition) over words that are presented intact (read words). In the first two experiments, a category instance generation task was used to test the possibility that the semantic features of generated words are more readily available than those of read words. This possibility was not supported. In Experiment 3, generation effects were found to depend on the level of meaningfulness of words in recall, but not in recognition. In Experiment 4, a between-list design eliminated the generation effect found in recall, but did not affect the generation effect in recognition. Taken together, these findings suggest that generating a target according to a letter transposition rule enhances the distinctiveness of the word along a nonsemantic dimension.
\end{abstract}

The term generation effect refers to the memory advantage found with verbal materials generated by a subject, as opposed to verbal materials presented to the subject intact by an experimenter. The subjects in experimental investigations of this effect typically are presented with a rule and a cue for generating the target (e.g., synonym: rapid-F for FAST), and the retention of the generated items is compared with that for the items that are presented intact. Generation effects have been reported with free recall, with cued recall and recognition, and with different rules (e.g., synonym, rhyme) for generating the target (Slamecka \& Graf, 1978).

Recently, McElroy (1987) suggested the possibility that generated words may receive greater semantic processing than read words even when the generation rule does not involve semantic processing. Such a view has an important implication for the finding that nonwords (which, by definition, must be generated according to a nonsemantic rule) do not yield generation effects (e.g., see Nairne, Pusen, \& Widner, 1985; Nairne \& Widner, 1987; Payne, Neely, \& Burns, 1986). That is, generation effects may not be obtained with nonwords, because semantic processing of nonwords is impossible.

In McElroy's (1987) first experiment, subjects read or generated homograph targets in response to rhyme cues (e.g., luck-duck). Subsequently, the subjects were given extralist cues that were related to either the dominant or the subordinate meaning of the homograph targets (e.g., swan or avoid). On the assumption that in the absence

This research was supported by a University of New South Wales postdoctoral fellowship to the author. I am grateful to the editor, Alice Healy, and to Fergus Craik, Reed Hunt, and an anonymous reviewer, for helpful comments on an earlier version of the article. Correspondence should be addressed to Sachiko Kinoshita, Department of Psychology, University of Wollongong, P.O. Box 1144, Wollongong, NSW 2500, Australia. of a biasing semantic context only the dominant meaning of a homograph is encoded (Simpson, 1981), McElroy reasoned that only the dominant meaning of the homograph target would be encoded in the presence of a rhyme cue. Also, since the meaning of the word cannot be known until the word is generated, any semantic processing must occur after that. McElroy supposed that if no postgeneration semantic processing occurred, then the dominant meaning of the target must be encoded to the same extent for read and generated targets, and that therefore no generation effect should be found when recall is cued with words that are related to the dominant meaning. However, McElroy found a recall advantage for generated words over read words when recall was cued with words related to the dominant meaning, yet not when recall was cued with words related to the subordinate meaning of the homographs. She concluded, therefore, that generated words received greater semantic processing than read words after the (dominant) meaning was encoded.

It may be pointed out that this is not the only interpretation open to the pattern of results reported by McElroy (1987). In particular, it can be suggested that the generation process in McElroy's experiment resulted in enhanced distinctiveness of the target, but that this enhanced distinctiveness may not have been mediated by greater semantic processing. This alternative interpretation is described below.

It is generally assumed that there are two stages in recall: an initial reconstruction process and a subsequent discrimination process (e.g., see Bahrick, 1970; Hunt \& Elliott, 1980). In the reconstruction process, a set of candidate items is generated on the basis of whatever retrieval cues are available. The candidate items are then subjected to a discrimination process. For familiar items such as words, the discrimination process is expected to involve the context in which the item was encoded (i.e., from 
previous extraexperimental encodings). Given that in previous extraexperimental encounters, words are more likely to have been read than generated, it seems reasonable to assume that the "generate" condition would form a smaller overlap with previous extraexperimental encodings than the "read" condition. In this sense, the generation process may be said to enhance the distinctiveness of the target.

In McElroy's (1987) first experiment, recall was found to be better overall (i.e., for both read and generated targets) when recall cues were related to the dominant meanings of target homographs than when they were related to the subordinate meanings. This effect of cue type may be suggested to have its locus in the reconstruction process: that is, a target is more likely to be included in the candidate set if the retrieval context matches the encoding context (cf. Wickens, 1987). If in the absence of a biasing semantic context only the dominant meaning of a homograph is encoded, the likelihood that a homograph target has been included in the set of candidate items should be greater when the recall cue is related to the dominant meaning than when it is related to the subordinate meaning of the target. In addition, if generation enhances distinctiveness of the target, as stated earlier, this information can be used to facilitate the discrimination process. It is to be expected, therefore, that a generation effect should be observed when recall cues are related to the dominant meaning of the homograph targets. However, when recall cues are related to the subordinate meaning, the likelihood of targets being included in the set of candidate items should be low. This should preempt the opportunity for distinctiveness to exert its effect, and therefore little generation effect should be expected in this case. It can be seen that the interaction between the effects of generation and cue type reported by McElroy does not have to be interpreted in terms of postgeneration semantic processing.

The aim in the present study was to investigate the locus of the memory advantage for words that are generated according to a nonsemantic rule, as opposed to words that are presented intact. The initial aim was to test whether the memory advantage for generated words is due to a greater semantic processing, as suggested by McElroy (1987). Experiment 1 was conducted to test the possibility that generating words according to a nonsemantic rule results in greater availability of the semantic features. In subsequent experiments, the possibility that the generation process enhances distinctiveness of the memory trace was examined, as was the mechanism underlying this enhancement.

\section{EXPERIMENT 1}

One consequence of greater semantic processing may be that the semantic features of a word become more readily available-that is, they come to mind more readily. If generated words receive greater semantic processing than read words, then the semantic features of generated words may be more readily available, thus increasing the opportunity for generated words to be included in a candidate set during recall. Experiment 1 was designed to test the possibility that generating a word according to a nonsemantic rule results in greater availability of semantic features of the word than does reading a word, using an implicit test of memory.

In an implicit memory test, no explicit reference is made to the specific episode in which the material has been learned (Schacter, 1987). For example, subjects may be presented with a stem of a word (e.g., win-), and asked to write down the first word that comes to mind that contains the stem (e.g., winter, window). Studies have shown that implicit tests are sensitive to a recent encounter with the stimulus materials: for example, a word is more likely to be produced in a word stem completion task if it has been presented recently.

Experiment 1 was made to consist of a category instance generation task, in order to test the notion that generating a target according to a nonsemantic rule nevertheless involves greater semantic processing. In such a task, subjects are presented with category names (e.g., furniture), and they are asked to produce instances of the category (e.g., chair). In a previous study that included this task (Graf, Shimamura, \& Squire, 1985), subjects (both amnesic and normal) were found to be more likely to respond with words that had been semantically processed earlier, relative to words that had not been presented (the subjects rated how much they liked each word). This finding may be taken to indicate that the category instance generation task is sensitive to semantic processing: because the semantic features of words are more readily available when the words have just been processed semantically, these words should be more likely to be produced in response to category names. From this, it may be expected that if generated words receive greater semantic processing than read words, then generated words will be more likely to be produced in the category instance generation task.

\section{Method}

Subjects. Thirty introductory psychology students at the University of New South Wales participated in Experiment 1, in return for course credits. Half of the subjects were tested for recall, and the other half were tested in the category instance generation task.

Materials. Thirty concrete nouns, selected from the Battig and Montague (1969) category norms, were used as targets. There were two criteria for selection as target: each word could belong to only one of the thirty categories chosen, and it could not be the most frequent response for that category (e.g., a precious stone-JADE; a piece of furniture- $\mathrm{COUCH}$ ). The thirty targets were divided into three sets, matched as closely as possible on frequency of production as the first response (mean production frequency $=29.26$ out of 442 respondents). The assignment of the sets to the "read," "generate," and "new" conditions was counterbalanced across subjects by means of a Latin square design, so that any one subject saw a target only once, and across every 3 subjects each target appeared in all three conditions.

Three versions of the response sheet were constructed, each containing 10 words in the "read" condition and 10 words in the "generate" condition. The words in the "read" condition were 
presented intact (e.g., JADE); the words in the "generate" condition had two letters transposed, which were indicated by underlining (e.g., JDAE). The "read" and "generate" conditions were mixed randomly

Procedure. There were three phases in the experiment: study, interpolated task, and test.

In the study phase, the subjects were presented with one of the three versions of the response sheet. They were told that there were 20 words on the sheet, half of which were correctly spelled, and the other half misspelled. It was further explained that the misspellings had been generated with the transposition of two letters of a word, which were underlined. The subjects were instructed to write the correct spelling next to each word given. Five seconds were allowed for each target.

Immediately after the study phase, the subjects were given an interpolated task to prevent active rehearsal of the material. They were instructed to continuously subtract 7 from the number 1,000 , and to write the answers on a provided sheet of paper. The interpolated task lasted for $30 \mathrm{sec}$.

Following the completion of the interpolated task, half of the subjects were given an unexpected test of recall, and the other half, a category instance generation task. In the recall test, the subjects were given a sheet of paper with 20 numbered spaces, and they were instructed to write down as many of the words that had been presented in the study phase as they could recall. The subjects were told to write the correct spelling of the word, irrespective of its original spelling. A maximum time limit of $3 \mathrm{~min}$ was set.

In the category instance generation task, the subjects were given a sheet of paper with 30 category names, and they were asked to write down an exemplar for each category. They were asked to respond with the first item that came to mind, and to complete the task as fast as they could. No mention was made of the relationship of the task to the study phase. There was no time limit for the task, but most subjects finished the task within $3 \mathrm{~min}$.

\section{Results}

Nine subjects ( 4 in the recall condition and 5 in the category instance generation condition) failed to generate all 10 targets during the study phase (averaged across all subjects, .33 out of 10 ). In the following analysis, the proportions of targets produced in the recall and the category instance generation task were conditionalized on correct generation during the study phase; however, the pattern of results did not change when analysis was carried out on unconditionalized data.

The conditionalized proportions of correct recall and the proportion of targets produced in the category instance generation task are displayed in Table 1 .

In the following and all subsequent analyses, all contrasts were planned, and the Bonferroni decision rule was used, with the alpha level set at .05. For recall, the contrast between the "read" and "generate" condition was significant $\left[F(1,14)=15.02, M S_{\mathrm{e}}=.016\right]$. That is, more generated targets than read targets were recalled. For the

Table 1

Proportion of Targets Produced in the Recall and Category Instance Generation Task in Experiment 1

\begin{tabular}{lccc} 
& \multicolumn{3}{c}{ Encoding Condition } \\
\cline { 2 - 3 } Task & Read & Generate & New \\
\hline $\begin{array}{l}\text { Recall } \\
\begin{array}{c}\text { Category instance } \\
\text { generation }\end{array}\end{array}$ & .18 & .36 & \\
\hline
\end{tabular}

number of targets produced in the category instance generation task, the contrast between the "read" and "generate" condition was nonsignificant $[F(1,14)<1.0]$. The contrast between old (mean of "read" and "generate" conditions) and new condition was significant $[F(1,14)$ $\left.=7.38, M S_{\mathrm{e}}=.008\right]$. That is, more targets were produced in the category instance generation task if they had been presented in the study phase than if they had not.

\section{Discussion}

The main finding in Experiment 1 was that there was no generation effect in the category instance generation task under a condition in which a generation effect was obtained with recall. However, before this finding may be taken as evidence that the generation of words according to a letter transposition rule does not involve greater semantic processing than does reading, it is necessary to consider the possibility that the category instance generation task is not sensitive to semantic processing.

The fact that "old" (both generated and read) words were more likely to be produced than "new" words (i.e., words that were not presented in the study phase) as exemplars (i.e., a repetition priming effect) indicates that the task is sensitive to a recent encounter with the words. However, it may be argued that this repetition priming effect does not reflect encoding of the semantic features of words, but rather that of the surface features. Indeed some experimenters (e.g., Graf \& Mandler, 1984; Jacoby, 1983) have found that implicit memory tasks such as word stem completion and perceptual identification tasks are insensitive to the level-of-processing manipulation.

Contrary to the preceding view, however, it should be pointed out that not all implicit memory tasks are insensitive to the amount of semantic processing. Roediger and Blaxton (1987) have reported results indicating that different types of implicit memory tasks are differentially sensitive to semantic processing. Using a word fragment completion task (e.g., C_P_E_-_COPPER) and a general knowledge test (e.g., "What constitutes $10 \%$ of yellow gold?' -COPPER), they found that although the repetition priming effect was greater for words presented without context at the study phase (e.g., XXXXXCOPPER) than for words that were generated by subjects in response to a semantic associate cue at the study phase (e.g., tin-C__ task, an opposite pattern was found in the general knowledge test. Roediger and Blaxton interpreted this finding as suggesting that whereas the performance in the word fragment completion task is sensitive to the processing of surface feature information (i.e., "data-driven" processing), the general knowledge test is sensitive to the processing of semantic information (i.e., "conceptually driven" processing).

In summary, it is not clear whether the absence of an effect of generation on the category instance generation task indicates a lack of sensitivity of the task to semantic processing, or a lack of difference in the amount of semantic processing involved in reading and generating a word according to a letter transposition rule. Experiment 2 was 
therefore conducted to test whether the category instance generation task was indeed sensitive to semantic processing, using two encoding conditions that are known to involve different amounts of semantic processing. The stimulus materials from Experiment 1 were again used. In one condition, the subjects were instructed to decide whether each word denoted a living or a nonliving thing, and in the other condition, the subjects decided whether or not each word contained the letter E. It was assumed that the former encoding condition required processing of the semantic features, but that the latter involved only minimal semantic processing (cf. Craik \& Tulving, 1975). Thus, it was expected that if the category instance generation task was sensitive to semantic processing, then the former encoding condition would produce greater repetition priming than would the latter encoding condition.

\section{EXPERIMENT 2}

\section{Method}

Subjects. An additional 24 subjects from the same population as in Experiment 1 participated in this experiment. Half of the subjects were assigned to the semantic encoding condition, and the other half were assigned to the orthographic encoding condition.

Materials. The target words were the 30 concrete nouns used in Experiment 1. The three versions of the response sheet employed in Experiment 1 were used in Phase 1, except that all words were presented intact (e.g., JADE). In the category instance generation task, the 30 category names in Experiment 1 were again used.

Procedure. There were three phases in the experiment: study, interpolated task, and test.

In the study phase, the subjects were presented with one of the three versions of the response sheet, and they were told that their task was to make decisions about each of the 20 words presented on the response sheet. Half of the subjects were assigned to the semantic encoding condition, and the other half to the orthographic encoding condition. The subjects in the semantic encoding condition were instructed to decide whether each word denoted a living or a nonliving thing, and to write $\mathrm{L}$ or $\mathrm{N}$, respectively, next to each word. The subjects in the orthographic encoding condition were instructed to decide whether or not each word contained the letter $\mathrm{E}$, and to write $\mathrm{Y}$ or $\mathrm{N}$, respectively, next to each word. Five seconds were allowed for each target.

The procedures for the interpolated task and the category instance generation task were identical to those in Experiment 1.

\section{Results}

The proportion of targets produced in the category instance generation task in each of the encoding conditions is displayed in Table 2.

Planned contrasts tested: (1) the main effect of encoding condition (semantic vs. orthographic); (2) the main

Table 2

Proportion of Targets Produced in Category Instance Generation Task in Experiment 2

\begin{tabular}{lccc}
\hline & \multicolumn{3}{c}{ Repetition Status } \\
\cline { 2 - 4 } Orienting Task & Old & New & Difference \\
\hline Semantic & .275 & .058 & .217 \\
Orthographic & .100 & .067 & .033 \\
\hline
\end{tabular}

effect of repetition status (old vs. new); and (3) the interaction between the two effects. The main effect of encoding condition was significant $\left[F(1,22)=8.088, M S_{\mathrm{e}}\right.$ $=0.010]$. That is, the subjects in the semantic encoding condition produced more target words than did the subjects in the orthographic encoding condition. The main effect of repetition status was significant $[F(1,22)=$ $15.764, M S_{\mathrm{e}}=0.012 \mathrm{]}$. That is, more old words were produced than new words. The interaction between the two effects was also significant $\left[F(1,22)=8.478, M S_{\mathrm{e}}\right.$ $=0.012]$. That is, the effect of repetition was greater for the semantic encoding condition than for the orthographic encoding condition.

\section{Discussion}

The results of Experiment 2 showed that subjects given a semantic orienting task (deciding whether each word denoted a living or nonliving thing) produced a greater repetition priming effect in the category instance generation task than did subjects given an orthographic orienting task (deciding whether each word contained the letter E). Consistent with Roediger and Blaxton's (1987) assertion, this finding indicates that some implicit memory tasks are sensitive to semantic processing, and it suggests in turn that the absence of a generation effect in the category instance generation task in Experiment 1 cannot be attributed to a lack of sensitivity of this task to semantic processing. ${ }^{1}$ Consequently, the finding of a recall advantage for words generated according to a letter transposition rule in Experiment 1 cannot be interpreted in terms of enhanced availability of the semantic features of the generated words.

It should be pointed out, however, that the present set of findings does not rule out the possibility that words generated according to a letter transposition rule receive greater semantic processing than read words do. Specifically, it may be argued that the category instance generation task is sensitive to minimal activation of semantic features. It is possible that both reading and generating a word result in the activation of the core meaning of the word, and that although a generated word receives greater semantic processing than a read word, the category instance generation task is not sensitive to this additional semantic processing over and above the minimal activation of the core meaning. To put it another way, the meanings of generated words may receive greater elaboration than do the meanings of read words, and the category instance generation task may not be sensitive to this elaboration.

If this line of reasoning is to be accepted, then, how does elaboration account for enhanced recall? According to Craik and Tulving (1975), elaboration involves the extraction of a number of different features that uniquely specify a word. If generated words receive greater semantic elaboration than read words do, then it may be that a greater number of semantic features (over and above the core meaning) are encoded for generated words. This possibility was examined in the next experiment. 


\section{EXPERIMENT 3}

Experiment 3 was designed to test the locus of the memory advantage observed with words that are generated according to a nonsemantic rule over read words. Specifically, the experiment followed the argument advanced by Hunt and Elliott (1980) in investigating the effect of orthographic distinctiveness. Hunt and Elliott tested recall and recognition of orthographically distinctive and nondistinctive words that were either high or low in associative meaningfulness (Noble, 1952; Paivio, Yuille, \& Madigan, 1968). Assuming a two-stage model of recall, consisting of an initial reconstruction process followed by a discrimination process, they supposed that meaningfulness affects the ease of initial reconstruction of targets. Presumably this is because the greater number of associates for words high in meaningfulness (or: high-meaningful words) provides a greater number of access routes to the episodic representation of the word. Hunt and Elliott further contended that if orthographic distinctiveness facilitates the discrimination process, then it should affect recall of high-meaningful words that are more likely to be generated as possible candidates in the reconstruction process, but not recall of the words low in meaningfulness (lowmeaningful words) that may fail to be reconstructed. In contrast, in recognition, the reconstruction process is assumed to play a limited role, because subjects are presented with the targets. Hunt and Elliott reasoned that orthographic distinctiveness should consequently facilitate recognition, irrespective of the level of meaningfulness of the target word.

The same logic regarding the effect of generation may be applied here. If a generation process that is guided by a nonsemantic rule enhances the distinctiveness of the target, but not necessarily via greater semantic elaboration, then a generation effect may be expected for recall of words that are high but not words that are low in meaningfulness; at the same time, a generation effect should be observed with recognition, irrespective of the level of meaningfulness of the target.

In contrast, if generated words receive greater semantic elaboration than read words do, then the same pattern of interaction between the effects of generation and meaningfulness should be obtained with recall and recognition. It may be expected that words high in meaningfulness should show a greater generation effect than would words low in meaningfulness, because semantic elaboration may be more difficult with low-meaningful words that have a limited semantic space. But if this should be the case, then there would be no reason to expect different patterns for recall and recognition, because greater semantic elaboration should lead to enhanced distinctiveness for words that are high but not words that are low in meaningfulness. In summary, if the enhanced distinctiveness for generated words relative to read words is due to greater semantic elaboration, then the same pattern of results is to be expected for recall and recognition; on the other hand, if the enhanced distinctiveness is not due to semantic processing, then the generation effect can be expected to depend on the level of meaningfulness in recall, but not in recognition.

\section{Method}

Subjects. An additional 20 subjects from the same population as in Experiments 1 and 2 participated in Experiment 3.

Materials. Sixteen high-meaningful $(m>6.12)$ and 16 lowmeaningful words ( $m<4.88$ ), selected from the Paivio et al. (1968) norms were used as targets. The high- and low-meaningful words were matched as closely as possible on frequency of usage (median frequency for high-meaningful words, 60.5 per million; for low-meaningful words, 61.0, according to the Kučera \& Francis, 1967, frequency count) and length (mean number of letters for highmeaningful words, 6.69; for low-meaningful words, 6.75). The high- and low-meaningful words were divided into Sets $A$ and $B$, each of which contained 8 words. The assignment of the sets to the "read" and "generate" conditions was counterbalanced across subjects, so that each subject saw a word only once, and across every pair of subjects, each word appeared in both the "read" and "generate" conditions.

In addition, 32 distractor words were used in the recognition test. Half of the distractor words were high-meaningful $(m>5.48)$ and the other half were low-meaningful $(m<4.96)$. The highmeaningful distractors ranged in frequency from 1 to 276 per million (median frequency, 8.5 per million) and the low-meaningful words, between 1 to 246 per million (median frequency, 8.0 per million), according to the KuXera and Francis (1967) frequency count. The distractors ranged between 4 and 10 letters in length (mean number of letters for high-meaningful words, 6.56 letters; for low-meaningful words, 6.44 letters).

Procedure. There were three phases in the experiment: study, interpolated task, and test.

The procedure for the study phase and the interpolated task was identical to that in Experiment 1, except that instead of 20 targets, 32 target words were presented in the study phase. In the test phase, all subjects were given a sheet of paper with 32 numbered spaces, and they were asked to write down as many of the target words as they could recall. A time limit of $4 \mathrm{~min}$ was set. Following recall, the subjects were given the recognition sheet, which contained the 32 target and 32 distractor words in a random order, and they were asked to circle the words that had been presented in the study phase. Although no formal time limit was set, most of the subjects completed the recognition test within $4 \mathrm{~min}$.

\section{Results}

Since there were no generation failures in Experiment 3 , the analysis was made on the basis of all items. The proportion of targets correctly recalled, the proportions of hits and false alarms, and the $d^{\prime}$ value (Hochhaus, 1972) in recognition are displayed in Table 3.

Table 3

Proportions of Targets Recalled, Hits, False Alarms, and $d^{\prime}$ in Experiment 3

\begin{tabular}{|c|c|c|c|c|}
\hline \multirow{3}{*}{$\begin{array}{l}\text { Encoding } \\
\text { Condition }\end{array}$} & \multicolumn{4}{|c|}{ Level of Meaningfulness } \\
\hline & \multicolumn{2}{|c|}{ High } & \multicolumn{2}{|c|}{ Low } \\
\hline & Read & Generate & Read & Generate \\
\hline $\begin{array}{l}\text { Proportion of } \\
\text { correct recall }\end{array}$ & .100 & .319 & .138 & 175 \\
\hline $\begin{array}{l}\text { Proportion of } \\
\text { hits }\end{array}$ & .638 & .850 & .600 & .763 \\
\hline $\begin{array}{l}\text { Proportion of } \\
\text { false alarms }\end{array}$ & \multicolumn{2}{|c|}{.188} & \multirow{2}{*}{\multicolumn{2}{|c|}{$1.078^{.275}$}} \\
\hline$d^{\prime}$ & 1.703 & 2.709 & & \\
\hline
\end{tabular}


Planned contrasts tested: (1) the main effect of encoding condition ("read" vs. "generate"); (2) the main effect of meaningfulness (high vs. low); and (3) the interaction between the two effects. For recall, the main effect of encoding condition was significant $[F(1,19)=14.932$, $\left.M S_{\mathrm{e}}=0.022\right]$. That is, more generated words than read words were recalled. The main effect of meaningfulness was also significant $\left[F(1,19)=8.435, M S_{\mathrm{e}}=0.056\right]$. That is, more words high in meaningfulness were recalled than were words low in meaningfulness. The interaction between the effects of encoding condition and meaningfulness level was also significant $\left[F(1,19)=17.774, M S_{\mathrm{e}}\right.$ $=0.009 \mathrm{~J}$. That is, the size of the generation effect was greater for words high, as opposed to words low, in meaningfulness.

For recognition, the value of $d^{\prime}$ was used in the analysis. The main effect of encoding condition was significant $\left[F(1,19)=20.090, M S_{\mathrm{e}}=.710\right]$. That is, more generated words than read words were recognized correctly. The main effect of meaningfulness was also significant $\left[F(1,19)=8.614, M S_{\mathrm{e}}=1.436\right]$. That is, words high in meaningfulness were recognized better than words low in meaningfulness. The interaction between the effects of encoding condition and level of meaningfulness was nonsignificant $[F(1,19)<1.0]$.

\section{Discussion}

The results of Experiment 3 showed that whereas in recall, a generation effect was found with words high, but not words low, in meaningfulness, a generation effect was found with both in recognition. This finding is consistent with the view that the generation process guided by a letter transposition rule enhanced a relatively late stage in the retrieval process: specifically, it enhanced the discrimination process, but not the reconstruction process. In contrast, the pattern of data is difficult to reconcile with the view that the generation process resulted in greater semantic elaboration of the targets.

The absence of a generation effect with recall of words low in meaningfulness has a parallel in previous failures to find a generation effect. Gardiner and Hampton (1985) used a transposition rule to generate, for example, letter bigrams (e.g., generate E.T. from $T E$ ) and noun compounds (e.g., generate tomato ketchup from ketchup tomato). They found a generation effect when the generated product was an integrated unit (e.g., E.T., tomato ketchup), but not when it was not a familiar unit (e.g., V.T., cheese ketchup). Similarly, Graf (1980) reported that, relative to reading an intact sentence, generating a sentence by transposing positions of content words of a given sentence did not result in better recall of the words when the generated sentence was semantically anomalous (e.g., The cheerful carpet exchanged the mouse). These findings indicate that when the generated material is not meaningful, no recall advantage is found with generated material as opposed to read material. Given the assumption that meaningfulness is an organizational variable that primarily affects the initial reconstruction process in recall, the findings, taken together with the results of the present experiment, suggest that a generation effect is contingent on a successful reconstruction of the material.

\section{EXPERIMENT 4}

Recently, in three separate studies, it was reported that a between-list manipulation of encoding condition ("read" vs. "generate") eliminated or greatly reduced the generation effect in recall (Begg \& Snider, 1987; Hirshman \& Bjork, 1988; Slamecka \& Katsaiti, 1987) and in recognition (Begg \& Snider, 1987). Although they emphasize somewhat different factors in their interpretations of this finding, these investigators have all suggested the possibility that a within-list manipulation of encoding condition inflates the apparent magnitude of generation effects by confounding encoding condition with the amount of attention an item receives. Specifically, when generating and reading conditions are mixed randomly in the same list, subjects' attention is drawn to the generated items with the result that less attention is expended on the read items. (But see Watkins \& Sechler, 1988, for evidence against the view that the generation effect is an artifact of deliberate differential allocation of attention to read and generated items.)

In the present experiments, encoding condition was always manipulated within lists, and the memory advantage observed with generated words was attributed to enhanced distinctiveness. It seems instructive to ask whether this enhancement is due solely to differential allocation of attention to generated and read items. To test this possibility, Experiment 4 was conducted. The same materials that were employed in Experiment 3 were used in a between-list design.

\section{Method}

Subjects. An additional 20 subjects from the same population as in the previous experiments participated in Experiment 4 . Half of the subjects were assigned to the "read" condition, and the other half, to the "generate" condition.

Materials. The materials used were identical to those used in Experiment 3, except that there were two versions of the response sheet for Phase 1 -one in which all words were presented intact (e.g., NEWSPAPER), and one in which all words had two letters transposed and underlined (e.g., NESWPAPER).

Procedure. The procedure was essentially identical to that in Experiment 3, except that encoding condition was manipulated between subjects. Thus, half of the subjects were instructed to copy each word, and the other half were instructed to generate the correct spelling of each word by transposing underlined letters.

\section{Results}

The proportion of targets correctly recalled, the proportion of hits and false alarms, and the value of $d^{\prime}$ are displayed in Table 4.

Planned contrasts tested: (1) the main effect of encoding condition ("read" vs. "generate"); (2) the main effect of meaningfulness (high vs. low); and (3) the interaction between the two effects.

For recall, the main effect of encoding condition was nonsignificant $\left[F(1,18)=1.531, M S_{\mathrm{e}}=0.006\right]$. The main effect of meaningfulness was significant $[F(1,18)$ 
Table 4

Proportion of Targets Recalled, Hits, False Alarms, and $d^{\prime}$ in Experiment 4

\begin{tabular}{lccccc}
\hline & \multicolumn{4}{c}{ Level of Meaningfulness } \\
\cline { 2 - 3 } \cline { 5 - 6 } $\begin{array}{l}\text { Encoding } \\
\text { Condition }\end{array}$ & Read & Generate & & Read & Generate \\
\cline { 2 - 3 } $\begin{array}{c}\text { Proportion of } \\
\text { correct recall }\end{array}$ & .231 & .300 & .119 & .113 \\
$\begin{array}{c}\text { Proportion of } \\
\text { hits }\end{array}$ & .706 & .850 & & .650 & .750 \\
$\begin{array}{c}\text { Proportion of } \\
\text { false alarms }\end{array}$ & .081 & .050 & & .181 & .081 \\
$d^{\prime}$ & 2.219 & 3.071 & 1.576 & 2.196 \\
\hline
\end{tabular}

$\left.=29.793, M S_{\mathrm{e}}=0.008\right]$. That is, more high-meaningful words than low-meaningful words were recalled. The interaction between these two effects was nonsignificant $\left[F(1,18)=1.862, M S_{\mathrm{e}}=0.008\right]$.

For recognition, the value of $d^{\prime}$ was analyzed. The main effect of encoding condition was significant $[F(1,18)=$ $\left.5.590, M S_{\mathrm{e}}=0.970\right]$. That is, generated words were recognized better than read words. The main effect of meaningfulness was also significant $[F(1,18)=19.104$, $\left.M S_{\mathrm{e}}=0.302\right]$. That is, high-meaningful words were recognized better than low-meaningful words. The interaction between these two effects was nonsignificant $[F(1,18)<1.0]$.

\section{Discussion}

In Experiment 4, a between-list manipulation of encoding condition eliminated the generation effect in recall that was observed with high-meaningful words with a withinlist design, but this did not remove the generation effect in recognition (for either high- or low-meaningful words). The recall data (for high-meaningful words) are consistent with the results of previous studies in which withinand between-list designs were compared, and in which it was found that recall level of generated words increased at the expense of read words in a within-list design (e.g., Begg \& Snider, 1987; Slamecka \& Kastaiti, 1987). These findings have been taken to suggest that when read and generated items are mixed in the same list, generated items receive a greater amount of attention at the expense of read items. However, it is not clear from the previous studies what specific process is engaged as a result of the differential allocation of attention. Specifically, the present recognition data indicating that a between-list design does not eliminate generation effects in recognition (see also McDaniel, Waddill, \& Einstein, 1988) suggest that any view that suggests that generated items in a mixed list are simply "processed more" at the expense of read items is inadequate. The finding in Experiment 1-namely, that no generation effect was found in the category instance generation task in a within-list design-also argues against the view that generated items, as a result of differential allocation of attention, are more "available" than are read items.
An interpretation that seems to fit the current data best suggests that in a within-list design, recall of read items suffers because of differential output interference during recall (cf. Rundus, 1973). Specifically, because generated words are more discriminable than are read words, they are more likely to be produced at recall. Assuming that recall involves a sampling process that is terminated after some number of unsuccessful attempts to yield a new item, and that the act of recalling an item blocks the sampling of other items, when read and generated items are mixed in the same list, one may expect the preferential recall of generated items to block the recall of read items. On the other hand, with a between-list design, there is no basis to expect differential output interference, and therefore there should be no recall advantage for generated items. $^{2}$

\section{GENERAL DISCUSSION}

The main findings in the present experiments show that generating a word according to a letter transposition rule (1) does not enhance the probability of the word's being produced in response to category names (Experiment 1); (2) results in greater recall if the word is high in meaningfulness, but not if the word is low in meaningfulness in a within-list design (Experiment 3); (3) does not result in greater recall for words either high or low in meaningfulness in a between-list design (Experiment 4); and (4) results in greater recognition, irrespective of the level of meaningfulness of the word in both within- and between-list designs (Experiments 3 and 4 ).

The finding of a generation effect in recall but not in the category instance generation task may be taken as evidence against the view that generating a word according to a letter transposition rule enhances the availability of the semantic features of the word. Rather, the generation process appears to enhance the distinctiveness of the encoded trace that facilitates discrimination once the target is reconstructed. The absence of a generation effect in recall but not in recognition provides support for this view. Finally, the finding of recall advantage for words that are high in meaningfulness and generated in a within-list design (but not in a between-list design) may be interpreted in terms of differential output interference for read and generated items in a mixed list that results from greater distinctiveness of the generated items.

It was suggested at the outset of this study that the dimension underlying the enhanced distinctiveness for generated words is nonsemantic. More specifically, it was argued that items generated according to a letter transposition mule are more distinctive than read items, because the generation condition has a smaller overlap with previous extraexperimental encodings. It should be emphasized that this enhanced distinctiveness results from a difference in the procedure involved in the letter transposition process and in reading an intact word (cf. Kolers \& Roediger, 1984). Evidence consistent with this view has 
been reported by Glisky and Rabinowitz (1985) and Nairne and Widner (1987, Experiment 2). These investigators have shown that recognition performance was enhanced for generated, but not for read, items when the same generation procedure was reinstated at retrieval.

A concluding comment is in order regarding the implication of the present interpretation for the finding of generation effects with nonwords. It has been well established (e.g., by Nairne et al., 1985; Nairne \& Widner, 1987; Payne et al., 1986) that generation effects are not obtained with nonwords. If generation enhances nonsemantic distinctiveness, why should the finding of generation effects be limited to words? Recently, however, Nairne and Widner (1987) reported evidence that when a nonword is generated according to a letter transposition rule, the functional product of generation may not be the whole nonword unit, but rather a fragment of the unit (e.g., the transposed letters). Furthermore, they showed that a generation effect with nonwords may be obtained when the retention test taps the functional product of generation. When subjects were asked to recognize the letters within nonwords that were underlined at encoding, they were better able to recognize the letters that were transposed at encoding than the letters that were copied (see also Graf, 1980, for a similar finding involving recognition memory for words within semantically anomalous sentences). It may be assumed that when meaningful items such as words are used as stimulus materials, the unit of generation may also be a fragment of the whole unit, but because meaning belongs to a whole unit (cf. Whittlesea \& Cantwell, 1987), the fragment becomes integrated with the whole unit. Thus, when recognition of whole units is required (as in a typical recognition test), generation effects are observed with words but not nonwords. These studies (see also Johns \& Swanson, 1988) point to an importance of the role of integration in the functional unit of generation. Future experimenters may do well to take this factor into account when they investigate generation effects.

\section{REFERENCES}

Bahrick, H. P. (1970). Two-phase model for prompted recall. Psychological Review, 77, 215-222.

Battig, W. F., \& Montague, W. E. (1969). Category norms for verbal items in 56 categories: A replication and extension of the Connecticut category norms. Journal of Experimental Psychology Monographs, 80(3, Pt. 2).

BEGG, I., \& SNider, A. (1987). The generation effect: Evidence for generalized inhibition. Journal of Experimental Psychology: Learning, Memory, \& Cognition, 13, 553-563.

Craik, F. I. M., \& Tulving, E. (1975). Depth of processing and the retention of words in episodic memory. Journal of Experimental Psychology: General, 104, 268-294.

GaRdiner, J. M., \& HaMPTON, J. A. (1985). Semantic memory and the generation effect: Some tests of the lexical activation hypothesis. Journal of Experimental Psychology: Learning, Memory, \& Cognition, 11, 732-741

Guisky, E. L., \& RABinowitz, J. C. (1985). Enhancing the generation effect through repetition of operations. Journal of Experimental Psychology: Learning, Memory, \& Cognition, 11, 193-205.
GRAF, P. (1980). Two consequences of generating: Increased inter- and intra-word organization of sentences. Journal of Verbal Learning \& Verbal Behavior, 19, 316-327.

Graf, P., \& Mandler, G. (1984). Activation makes words more accessible, but not necessarily more retrievable. Journal of Verbal Leaming \& Verbal Behavior, 23, 553-568.

Graf, P., Shimamura, A., \& Squire, L. (1985). Priming across modalities and priming across category levels: Extending the domain of preserved function in amnesia. Journal of Experimental Psychology: Learning, Memory, \& Cognition, 11, 386-396.

Hirshman, E., \& BJoRK, R. A. (1988). The generation effect: Support for a two-factory theory. Joumal of Experimental Psychology: Learning, Memory, \& Cognition, 14, 484-494.

Hochraus, L. A. (1972). A table for the calculation of $\mathrm{d}^{\prime}$ and B. Psychological Bulletin, 77, 375-376.

Hunt, R. R., \& Ellott, J. M. (1980). The role of nonsemantic information in memory: Orthographic distinctiveness effects on retention. Journal of Experimental Psychology: General, 109, 49-74.

JACOBY, L. L. (1983). Remembering the data: Analyzing interactive processes in reading. Journal of Verbal Learning \& Verbal Behavior, $22,485-508$.

Johns, E. E., \& SWANSON, L. G. (1988). The generation effect with nonwords. Journal of Experimental Psychology: Learning, Memory, \& Cognition, 14, 180-190.

Kolers, P. A., \& Roediger, H. L. III. (1984). Procedures of mind. Journal of Verbal Learning \& Verbal Behavior, 23, 425-449.

KuČERA, H., \& FranCIs, W. N. (1967). Computational analysis of present-day American English. Providence, RI: Brown University Press.

McDaniel, M. A., Waddill, P. J., \& Einstein, G. O. (1988). A contextual account of the generation effect: A three-factor theory. Journal of Memory \& Language, 27, 521-536.

McELroY, L. A. (1987). The generation effect with homographs: Evidence for postgeneration processing. Memory \& Cognition, 15, 148-153.

Nairne, J. S., Pusen, C., \& Widner, R. L., JR. (1985). Representation in the mental lexicon: Implications for theories of the generation effect. Memory \& Cognition, 13, 183-191.

NAIRNE, J. S., \& WIDNER, R. L., JR. (1987). Generation effects with nonwords: The role of test appropriateness. Journal of Experimental Psychology: Learning, Memory, \& Cognition, 13, 164-171.

NoBle, C. E. (1952). An analysis of meaning. Psychological Review, 59, $421-430$.

Paivio, A., Yullle, J. C., Madigan, S. A. (1968). Concreteness, imagery, and meaningfulness values for 925 nouns. Journal of Experimental Psychology Monographs, 76(1, Pt. 2), 1-25.

Payne, D. G., Neely, J. H., \&urns, D. J. (1986). The generation effect: Further tests of the lexical activation hypothesis. Memory \& Cognition, 14, 246-252.

RoEDIGER, H. L. III, \& BLAXTON, T. A. (1987). Retrieval modes produce dissociations in memory for surface information. In D. S. Gorfein \& R. R. Hoffman (Eds.), Memory and learning: The Ebbinghaus Centennial Conference (pp. 349-380). Hillsdale, NJ: Erlbaum.

Rundus, D. (1973). Negative effects of using list items as recall cues. Journal of Verbal Learning \& Verbal Behavior, 12, 43-50.

SCHACTER, D. L. (1987). Implicit memory: History and current status. Journal of Experimental Psychology: Learning, Memory, \& Cognition, 13, 501-518.

Simpson, G. B. (1981). Meaning dominance and semantic context in the processing of lexical ambiguity. Journal of Verbal Learning \& Verbal Behavior, 20, 120-136.

Slamecka, N. J., \& Graf, P. (1978). The generation effect: Delineation of a phenomenon. Journal of Experimental Psychology: Human Learning \& Memory, 4, 592-604.

SlameCKa, N. J., \& Katsaiti, L. T. (1987). The generation effect as an artifact of selective displaced rehearsal. Joumal of Memory \& Language, 26, 589-607.

Watkins, M. J., \& Sechler, E. S. (1988). Generation effect with an incidental memorization procedure. Journal of Memory \& Language, 27, 537-544. 
Whittlesea, B. W. A., \& CANTWEll, A. L. (1987). Enduring influence of the purpose of experiences: Encoding-retrieval interactions in word and pseudoword perception. Memory \& Cognition, 15, 465-472.

WiCKENS, D. D. (1987). The dual meaning of context: Implications for research, theory, and applications. In D. S. Gorfein \& R. R. Hoffman (Eds.), Memory and leaming: The Ebbinghaus centennial conference (pp. 135-152). Hillsdale, NJ: Erlbaum.

\section{NOTES}

1. It may be noted that the finding of a generation effect in recall but not in the category instance generation task is at odds with the prediction that is to be expected on the basis of Roediger and Blaxton's (1987) assertion that the two tasks should show the same effects of generation because they are both conceptually driven tasks. Specifically, since the letter transposition process is not conceptually driven, Roediger and Blaxton would predict no generation effect for either task. As will be argued later, the recall advantage for generated words found with a withinlist design is best explained in terms of differential output interference for read and generated items in a mixed list. With this additional assumption, the present results can be accommodated within Roediger and Blaxton's transfer-appropriate processing framework for interpreting implicit and explicit memory tasks

2. It is interesting to note that Hunt and Elliott (1980) also compared the within- and between-list manipulation (of orthographic distinctiveness) and reported finding no effect of orthographic distinctiveness in recall with a between-list design. They also considered, and rejected, the differential allocation of attention explanation of the orthographic distinctiveness effect. However, they concluded that the within-list design was a necessary condition for finding the effect of orthographic distinctiveness, because subjects' attention must be drawn to the different levels of orthographic distinctiveness for this feature to be encoded. Since they only used recall in comparing within- and between-list designs, it would be interesting to test whether an effect of orthographic distinctiveness may be obtained with a between-list design in recognition.

(Manuscript received April 25, 1988; revision accepted for publication January $27,1989$. ) 